\title{
O transnacional na história da educação'
}

\author{
Eugenia Roldán Vera ${ }^{2}$ \\ ORCID: 0000-0003-2049-6464 \\ Eckhardt Fuchs ${ }^{3}$ \\ ORCID: 0000-0003-3394-3147
}

\section{Resumo}

Este artigo discute pesquisas recentes em história transnacional da educação com ênfase nas categorias centrais com base nas quais os objetos de estudo são construídos. Orientados pela história dos conceitos e pela semântica histórica, traçamos, primeiramente, a emergência do campo da história transnacional da educação, na confluência entre o conceito historicamente formado de educação internacional e o projeto de pesquisa transnacional nas ciências históricas. Em seguida, apresentamos uma visão geral das tendências recentes nesse campo específico, considerando áreas de estudo e abordagens teórico-metodológicas. Argumentamos que a construção histórica do transnacional tem influência nos modos pelos quais formulamos nossas questões de pesquisa, e lançamos um convite a continuar esta autorreflexão sobre outros conceitos e categorias em história da educação.

\section{Palavras-chave}

História da educação - História transnacional - Educação internacional - História dos conceitos- Transferência cultural.

\footnotetext{
1- A proposta de tradução decorreu da oferta da disciplina IEB 5046 - História transnacional da escola: circulação de sujeitos, saberes e artefatos (séculos XIX-XX), no primeiro semestre de 2020, no Programa de Pós-Graduação do Instituto de Estudos Brasileiros (USP), e integra as atividades do Projeto Temático Saberes e Práticas em fronteiras: por uma história transnacional da educação (1810-...), processo FAPESP 2018/26699-4.

Proposta, organização e revisão técnica da tradução: Diana Gonçalves Vidal; Alexandre Ribeiro e Silva ; Ana Carolina Carvalho Guimarães.

2- Cinvestav, Cidade do México, México. Contato: eroldan@cinvestav.mx

3-Technical University Braunschweig, Braunschweig, Alemanha. Contato: fuchs@gei.de
} 


\section{The transnational in the history of education}

\section{Abstract}

This article discusses recent research in transnational history of education with an emphasis on the categories that lay at the core of the way in which objects of study are constructed. Oriented by the history of concepts and historical semantics, we first trace the emergence the field of transnational history of education in the confluence of the historically-formed concept of international education and of the transnational research project in historical sciences. We then present an overview of recent trends in this particular field, considering both study areas and theoretical and methodological approaches. We argue that the historical construction of the transnational has an influence in the ways in which we formulate our research questions, and launch an invitation to continue this self-reflexivity into other concepts and categories of the history of education.

\section{Keywords}

History of education - Transnational history - International education - History of concepts - Cultural transfer.

\section{O Conceito de transnacional}

Nosso ponto de partida é o pressuposto de que a linguagem que usamos para falar sobre a realidade não apenas descreve a realidade, mas dela é constitutiva. Isto é, ao falarmos de arena internacional, de esfera global ou de espaço transnacional, não estamos simplesmente descrevendo algo que existe; estamos tornando inteligivel uma experiência da realidade e simultaneamente construindo uma abstração dessa realidade. Conceitos são mecanismos por meio dos quais articulamos e mobilizamos a experiência da realidade; são palavras que condensam um vasto número de experiências e, tornando-se abstratas, criam espaço mais amplo de significação (KOSELLECK, 2004). Alguns conceitos desenvolvem um maior nível de abstração e se tornam categorias analíticas nas ciências sociais; a articulação de várias ideias em conceitos orienta a maneira pela qual definimos nosso objeto de estudo e conduzimos as pesquisas.

Tomamos como premissa da história das linguagens políticas e educacionais a suposição de que a língua constitui o conjunto de regras de um sistema de pensamento dado historicamente, regras que determinam o que é possível - e o que não é possível - perceber, discutir e analisar em relação a um certo tópico (SKINNER, 2002; POCOCK, 1989; TRÖHLER, 2011). Alinhados a esta premissa, começamos perguntando: desde quando tem sido possível pensar sobre um domínio transnacional, e como? Quando e por que começamos a pensar "transnacionalmente" ou "internacionalmente" em educação? Quais conceitos a ele relacionados usamos para falar desse domínio que está além da nação, e o que eles evocam? Quais condições históricas e historiográficas nos permitem pensar que pesquisar o transnacional é possível? 
Também tomamos da história conceitual e da semântica histórica a suposição de que os conceitos carregam uma camada de significados passados que podem se sobrepor em seus diferentes usos por vários atores (KOSELLECK, 2004). Reconhecemos que as características abstratas dos conceitos permitem sua transferência através de regiões geográficas, disciplinas e culturas acadêmicas, e que no processo de sua transferência seus significados mudam, como vários estudos sobre os conceitos "em viagem" ou "nômades" demonstraram (BAL, 2002; CHRISTIN, 2010).

0 caráter abstrato, social e histórico dos conceitos torna-os necessariamente ambíguos, polissêmicos, e abertos à discordância e ao debate. Se levarmos em conta o componente performativo da linguagem (AUSTIN, 1962), veremos que os significados dos conceitos também são afetados pelo fato de serem invocados para diferentes propósitos, a serviço de diferentes agendas, dentro de diferentes marcos teóricos ou políticos e em diálogo com interlocutores específicos. Não obstante, os conceitos permanecem "a ferramenta da intersubjetividade": "eles facilitam a discussão com base em uma linguagem comum" (BAL, 2002, p. 22). Não porque eles signifiquem o mesmo para todos, mas, precisamente, porque eles evocam coisas muito diferentes, sobrepostas em um substrato compartilhado, o que possibilita a discussão acadêmica. Nossa intenção ${ }^{4}$ é, portanto, historicizar e problematizar as próprias categorias que usamos em nossas pesquisas em uma história da educação que se estende além da nação como unidade de análise. Neste texto, assim, examinamos primeiro o surgimento do que é conhecido como "história transnacional da educação" na confluência de discursos e conceitos sobre educação internacional e o projeto de pesquisa transnacional nas ciências históricas. Em seguida, apresentamos uma visão geral de pesquisas transnacionais recentes na história da educação, considerando áreas de estudo e abordagens teóricas e metodológicas ${ }^{5}$.

\section{Uma história transnacional da educação: entre a educação internacional e a pesquisa histórica transnacional}

Se voltarmos nossa atenção para os termos usados para descrever - e assim construir - uma "realidade transnacional", precisamos primeiro diferenciar entre duas esferas de referência distintas que foram construídas no que denominamos atualmente de uma "abordagem transnacional" em história da educação. A primeira delas é um discurso em educação que emergiu no alvorecer do século XIX e que utilizou os termos "internacional" e "internacionalismo". "Internacional”, há cento e trinta anos, referia-

4- N.T:: Os autores se referem ao capítulo introdutório, bem como ao conjunto dos textos reunidos no livro.

5- N.T.: Conforme informado anteriormente, a última sessão, em que se apresentam os demais capítulos que compõem o livro, foi suprimida da presente tradução. São eles: "The Transnational and Transcultural: Approaches to Studying the Circulation and Transfer of Educational Knowledge", por Christine Mayer; "Day Nurseries in Europe in the Nineteenth and Twentieth Centuries: The Challenge of the Transnational Approach", por Dorena Caroli; "Conversations About the Transnational: Reading and Writing the Empire in the History of Education", por Rebecca Rogers; "Transnationalism and the Engagement of Empire: Precursors of the Postcolonial World", por Tim Allender; "Adaptations of Adaptation: On How an Educational Concept Travels from the Heartlands to the Hinterlands", por Elsie Rockwell; "Analyzing Toru Dutt's Oeuvre Today: How a Transnational LiteraryEducational Case from Colonial India Can Enrich Our Conception of Transnational History", por Barnita Bagchi; "Temporalities and the Transnational: Yoshi Kasuya's Consideration of Secondary Education for Girls in Japan" (1933), por Joyce Goodman; "(De)Constructing the Global Community: Education, Childhood and the Transnational History of International Organizations", por Damiano Matasci e Joëlle Droux; e "Transnational as Comparative History: (Un)Thinking Difference in the Self and Others", por Thomas S. Popkewitz. 
se à esfera do estado e à sua política externa em relação a outros estados; o conceito de "educação internacional" apareceu pela primeira vez na virada do século XIX para o século XX e continuou dominando a semântica dos discursos nacionais e globais sobre a educação até hoje. A segunda esfera de referência que podemos associar a uma história transnacional da educação é uma abordagem de pesquisa. Recentemente, o uso da perspectiva transnacional em história da educação permitiu descrever fenômenos que transcendem a escala nacional, ainda que não tenham sido percebidos como transnacionais por aqueles que os experimentaram. Essa perspectiva sinalizou para outras dimensões do processo educacional. A seguir, faremos uma breve história do discurso e dos conceitos relacionados a essas duas esferas de referência.

\section{O discurso sobre “Educação internacional”: um campo de pesquisa emerge}

0 desenvolvimento de um discurso sobre internacionalismo está estreitamente ligado à emergência dos Estados-Nação e seus processos de modernização que começaram na segunda metade do século XIX. Tanto o adjetivo "internacional” quanto o substantivo "internacionalismo" podem ser rastreados até o século XVIII, apesar dos termos não aparecerem nos dicionários franceses e ingleses até o terço final do século XIX (FARIES, 1915). Desde sua emergência, o termo "internacionalismo" abrangeu uma gama de significados, todos relacionados a um domínio das relações entre as Nações. Primeiro, referiu-se aos limites de esferas nacionais e defınidas pelo estado, e a clamores por soberania no contexto da regulação da relação entre os estados. Segundo, fez parte do discurso do movimento operário. Terceiro, foi anexado como um epíteto de uma era caracterizada por relações internacionais que desde a segunda metade do século XIX têm sido cada vez mais interligadas, relações estas promovidas por organizações governamentais e não governamentais ${ }^{6}$. E quarto, o termo apareceu em discursos acadêmicos refletindo a visão dos acadêmicos sobre eles mesmos como membros de uma "comunidade imaginada" (ANDERSON, 1991), compartilhando um consenso de que a cooperação internacional era uma condição normativa da produção e circulação de conhecimento. Uma concepção dominada pela ciência, em relação aos seus efeitos societais, como fundamentalmente a serviço do progresso da humanidade e do desenvolvimento da comunicação e harmonia entre as nações (FOX, 2016; RAYWARD, 2014; FORMAN, 1973; METZLER, 2000). Esse universalismo acadêmico, com a implicação de que a pesquisa acadêmica era "internacional”, pressupôs a existência de uma metodologia universalista única, considerou a pesquisa acadêmica um meio abstrato para alcançar o conhecimento universal e o progresso geral - mas não como uma atividade prática ou uma instituição social -, e presumiu que o valor abstrato da "internacionalidade" representava a base real e inegociável sobre a qual os acadêmicos conduziam seu trabalho.

0 discurso internacionalista em educação surgido na virada do século XIX para o século XX foi igualmente marcado por um tom normativo dominante. Na

6 - Ver: Oxford English Dictionary (1989, p. 1124); Laqua (2013); Sluga (2013); Friedemann e Hölscher (1982); Rittberger e Zangl (2003); Boli e Thomas (1999). 
Alemanha, o conceito de uma "educação mundial" (KOBEL, 1919) foi desenvolvido a partir do pressuposto de que a aspiração universal da educação a defender os valores da humanidade tornou possível uma teoria e prática da educação global unificada. Essa teoria, articulada no contexto das Conferências de Paz de Haia, exigia uma educação universal no espírito de paz e harmonia entre os povos do mundo e atraiu entusiástica concordância particularmente de educadores de esquerda e reformistas da década de 1920, que acreditavam que uma implementação bem-sucedida de uma educação internacional era possivel somente no interior do contexto da Liga das Nações ou de acordo com seus objetivos (TACKE, 1924). Nesse ponto de vista, a principal tarefa da educação internacional e das relações internacionais que a sustentavam consistia em educar as próximas gerações no espírito de paz e harmonia entre os povos.

Uma discussão relacionada girou em torno da revisão de livros didáticos e da educação para a paz em sala de aula como base para a educação internacional; essas questões também foram centrais para a discussão entre professores de história sobre métodos educacionais específicos a cada assunto. Essa combinação de educação internacional com uma abordagem educacional orientada pela Liga das Nações, fundada no pacifismo e em pedagogias reformistas/progressistas, atraiu críticas de conservadores da era Weimar, que rejeitavam o sistema do Tratado de Versalhes e a ordem mundial do pós-guerra (OESTREICH, 1931).

0 conceito de "internacionalismo educacional" englobava uma missão humanitária geral, cujo cerne era a suposição de que o tipo "certo" de educação tinha os mesmos princípios básicos universais em todas as nações e para toda a humanidade. Foi nesse espírito que Franz Kemény, escrevendo em 1914, descreveu os dois objetivos do ensino internacional: “a) o objetivo utilitário consiste no que se pode aproveitar de instituições estrangeiras para o progresso do próprio país; b) o objetivo ético se resume na abolição do isolamento e das fronteiras culturais para ai estabelecer um relacionamento mais frequente entre os povos e uma troca mais múltipla de seus produtos espirituais" Kemény, "a confirmação pedagógica do ensino internacional é dada pelo ideal supremo da própria educação: pela humanitas” (KEMÉNY, 1914). A noção abstrata de humanidade e cosmopolitismo que apareceu fazia referência a uma agenda do Iluminismo; esse movimento de reviver o espírito cosmopolita da pré-modernidade foi uma tentativa de compensar o impacto negativo das práticas das nações industriais modernas e, assim, prevenir guerras. 0 meio para alcançar essa missão de educação centrada na humanidade consistia em professores transmitindo educação para a paz. Essas ideias surgiram simultaneamente e de forma relativamente independente na Europa e nos EUA. ${ }^{8}$

Em conexão com a educação internacional enquanto um conceito orientado para a defesa da paz e do desenvolvimento, um campo de pesquisa em educação internacional surgiu, amplamente relacionado ao da educação comparada. A emergência desses campos conectados geralmente é situada na França, no início do século XIX. Na década de 1810, Marc-Antoine Jullien descreveu a ciência da educação como resultante da comparação de

7-N.T.: No original: "a) le but utilitaire consiste en ce qu'on profite des institutions étrangères pour les progrès des son propre pays; b) le but éthique se résume dans l'abolition de l'isolement et des frontières culturales pour y établir un rapport plus fréquent entre les peuples et un échange plus multiple de leurs produits spirituels." Na sequência, lê-se: "la confirmation pedagogique de l'enseignement international est donne par l'ideal supreme de l'education meme: par la humanitas".

8- Consultar: Encyclopedia of Educational Research (1950, p. 617-627). 
informações estatísticas produzidas pelos governos de vários países sobre financiamento para educação, matrícula de alunos, número de professores e outros aspectos dos sistemas educacionais. Em 1808, César Auguste Basset convidou estudiosos "livres de preconceitos nacionais" a observar a educação fora da França "com a intenção de fazer recomendações para o sistema educacional francês” (CROSSLEY; WATSON, 2003). Um século depois, a criação do Bureau Internacional de Educação em Genebra (1925), e, depois, da UNESCO (1945), deu forma material a essa aspiração à produção e coleta sistemática de dados educacionais de todo o mundo, impulsionada pelo pressuposto de que essa coleção promoveria a conscientização e o entendimento internacional entre os países. Em meados do século XX, "educação internacional" se referia à pesquisa sobre "outros sistemas, políticas, práticas e filosofias educacionais” fora do domínio geográfico anglo-saxão e da Europa ocidental, particularmente nos países em desenvolvimento (LITTLE, 2010). As sociedades americanas e britânicas de educação comparada acrescentaram o termo "internacional" a seus nomes em 1968 e 1983, respectivamente, em um esforço para aproximar estudiosos trabalhando sobre educação em sociedades industrializadas e aqueles pesquisando educação em países em desenvolvimento (BRAY, 2010).

0 campo de "educação comparada e internacional" estava, portanto, em débito com a premissa de que havia alguns valores humanitários universais que todas as nações poderiam inculcar por meio da educação para o avanço da paz; esse paradigma em parte alimentou a suposição de que países poderiam aprender uns com os outros em termos de políticas e filosofias educacionais e que estas últimas poderiam ser transferidas de um contexto para o outro para promover o desenvolvimento, pois, em última análise, todos estavam em estágios diferentes do mesmo caminho para a civilização ou modernização (STEINER-KHAMSI, 2002; HÉBERT; ABDI, 2013). Esse paradigma e as premissas relacionadas se tornaram muito menos explícitos e passaram por uma crítica considerável nas últimas três décadas, com o foco do campo cada vez mais voltado para a transmissão transcultural do conhecimento educacional e para as implicações políticas, sociais e econômicas das tendências voltadas à internacionalização da educação (em parte como uma reação às premissas universalistas anteriores). ${ }^{9}$

0 conceito de globalização desempenhou um papel fundamental na teorização realizada no campo da educação comparada e internacional nas últimas duas décadas. Considerando que, como será discutido na próxima seção, a globalização tende a ser vista como o avanço progressivo da interconectividade internacional e da convergência transnacional da organização e do intercâmbio educacionais, alguns estudiosos convocaram o campo a prestar atenção à maneira dependente do contexto pela qual teorizamos a globalização na educação. Refletindo sobre o importante papel que "o discurso educacional desempenha na configuração da realidade educacional do mundo atual” (SCHRIEWER, 2003, p. 271), e orientado pela sociologia do conhecimento de Luhmann, Jürgen Schriewer argumentou que a maneira pela qual teorizamos a educação é uma "reflexão autorreferencial do subsistema particular de educação da sociedade perseguido no interior desse sistema” (SCHRIEWER, 2003, p. 276). ${ }^{10}$ A teorização

9- Embora o rótulo "educação internacional" ainda seja dominante, alguns começaram a usar "educação supranacional" para descrever esse tipo de pesquisa. Consultar: Valle (2013).

10- Ver também: Schriewer (2009). 
educacional é, portanto, "enraizada e determinada pelas diferentes condições contextuais, pelos problemas e questões particulares e pelas tradições intelectuais e sistemas de valores distintos característicos de seu respectivo sistema de referência e do contexto de reflexão relacionado" (SCHRIEWER, 2003, p. 276).

\section{Abordagens históricas transnacionais}

Enquanto o "internacionalismo" tem sido há muito tempo um campo de pesquisa nas ciências políticas, especialmente no que diz respeito aos estudos de regime internacional, foi somente no final do século XX que o termo "transnacional" encontrou seu caminho na pesquisa histórica, especialmente no contexto dos debates sobre a história mundial e global nos EUA. 0 objetivo que impulsionou a introdução do termo, um desejo de pôr em questão o foco tradicional da história acadêmica nos processos relacionados a Estados-Nação, não deu, é claro, necessariamente ao conceito um status de isento de juízo de valores. 0 conceito de "transnacional" tem uma história mais curta que o de "internacional" e também sofreu deslocamentos semânticos significativos. Foi cunhado nos EUA no início do século XX: o agora famoso ensaio "Transnational America”, escrito pelo intelectual radical Randolph Bourne em 1916, usou o termo para se referir positivamente à diversidade de origens entre a população americana (o que chamamos, atualmente, de "multiculturalismo"), celebrando o excepcionalismo dos EUA no concerto das nações do mundo (BOURNE, 1916). 0 termo, então, se expandiu para o domínio do direito privado (como “direito transnacional”), na década de 1950, e para a economia na década de 1970, referindo-se aqui, em particular, à esfera de ação das corporações multinacionais, uma esfera sem jurisdição nacional, não sujeita ao controle de qualquer tipo de corpo governamental. Organizações não-governamentais adotaram o termo na década de 1980. Na década de 1990, entrou no campo educacional, onde "educação transnacional" passou a significar o oferecimento de programas de estudos em educação (superior) ou serviços educacionais por instituições localizadas em um país para estudantes de outro país (COUNCIL OF EUROPE, 2001). Em todos esses campos, o termo "transnacional" não é necessariamente neutro. Pode ser associado tanto à celebração de alguma forma de mistura intercultural quanto à condenação de uma agenda econômica em expansão, que atinge cruelmente as estruturas locais e nacionais e não reconhece a jurisdição nacional.

0 que foi denominado de "virada transnacional" (CLAVIN, 2005) provocou importantes desenvolvimentos nos estudos históricos nas últimas duas décadas (IRIYE; SAUNIER, 2009; PERNAU, 2011; SAUNIER, 2013; BAYLY et al., 2006; IRIYE, 2013). A "história transnacional" emergiu no contexto de processos de integração econômica e política, a partir do terço final do século XX, que levantaram questões de governança supranacional, territorialidade e soberania, além, ou como uma extensão, do EstadoNação. Essas questões levaram a uma transformação das maneiras pelas quais construímos nossos objetos de estudo (MIDDELL; NAUMANN 2010). Entrelaçamentos ${ }^{11}$

11- N.T.: Entanglemente entangled foram aqui traduzidos por entrelaçamento e entrelaçada. 0 termo tem difícil tradução ao português. Consiste em uma perspectiva histórica, como exposto pelos autores no artigo. No Brasil, emerge traduzido também em alguns textos como emaranhamento e emanharada. No entanto, parece prevalecer a opção aqui adotada. 
supranacionais e redes deram origem à construção de estratégias analíticas que vão além das narrativas nacionais, muitas vezes invocando procedimentos interdisciplinares que conectam perspectivas da história, das ciências sociais e da economia. Tomando como ponto de partida a dissolução de uma ordem espacial hierárquica orientada em função do Estado-Nação, a proliferação de atores sociais e políticos, e a pluralidade de espaços em que operam, o neologismo "globalização" surgiu para definir o processo dialético de reterritorialização e desterritorialização, formando, assim, o ponto de partida para as tendências recentes em história global e transnacional (IRIYE, 2013; COHEN; O'CONNOR, 2004; BACH, 2013).

A "história transnacional" tende a ser diferenciada da "história internacional", que, embora estabelecida há muito tempo, é geralmente utilizada no contexto da história diplomática, com foco no estado ou outros atores institucionalizados. "História global" e "história transnacional" são frequentemente usadas como sinônimos, ainda que tendam a diferir nas maneiras como lidam com o espaço e a territorialidade. "História global" levanta questões referentes a um domínio supranacional, como governança e soberania global; desterritorializa as nações e redefine o espaço, criando unidades de análise regionais ou locais que vão além e fora dos limites do Estado-Nação. Esse entendimento do "global" permite a aplicação dessa abordagem a um número crescente de períodos históricos, desde os tempos antigos até a chamada "história da globalização", do século XIX ao XXI. "História transnacional", embora também se refira a uma história que atravessa fronteiras e considera atores estatais e não estatais (em oposição à "história internacional”, baseada em atores estatais ou institucionalizados), é espacialmente mais restrita: ela não desconstrói a nação - pressupõe sua existência e estuda seu desenvolvimento como um fenômeno global - mas contextualiza-a em um conjunto de relações de tradução, entrelaçamentos e dependências. Isso significa que o termo "transnacional" tende a ser aplicado principalmente à ordem mundial moderna dos Estados-Nação, em vez de sociedades modernas ou pré-modernas primárias (DRAYTON; MOTADEL, 2018; BAGCHI; FUCHS; ROUSMANIERE, 2014; ACEVEDO; QUINTANILLA, 2009). Como Ian Tyrrell observou, a história transnacional nos EUA foi considerada menos e mais do que a história global no sentido de que "nem toda história através das fronteiras nacionais é global ou o produto da globalização, mas todas - pelo menos para a história contemporânea são transnacionais" (TYRRELL, 2009). Mais recentemente, "entangled history" (um termo melhor estabelecido em inglês do que o anterior histoire croisée ou "shared history") tornou-se cada vez mais importante para descrever uma maneira de fazer história que não apenas examina os fluxos multidirecionais supranacionais, mas também reflete e explicita as condições (entrelaçadas) nas quais os historiadores constroem seus objetos transnacionais de pesquisa (WERNER; ZIMMERMANN, 2003).

A dissolução da ordem espacial levou os historiadores globais e transnacionais a fazerem uso de cinco tipos diferentes de narrativas, muitas vezes combinando mais de uma ao mesmo tempo: (1) Narrativas de divergência mostram como processos derivados da mesma origem se diversificaram ao longo do tempo e espaço; (2) Narrativas de convergência descrevem como os fenômenos ocorridos em lugares distantes eram substancialmente semelhantes, ou se tornaram assim com o tempo; (3) Narrativas de contágio se concentram na transferência ou disseminação de fenômenos e processos 
através das fronteiras nacionais; (4) Narrativas de sistemas buscam explicar os padrões nos quais estruturas sociais e históricas interagem e se influenciam mutuamente (CROSSLEY, 2007); e (5) Narrativas de entrelaçamento tentam mostrar a influência contínua exercida por atores, fenômenos e processos transnacionais sobre as dinâmicas do "nacional".

A pesquisa em história transnacional ou global geralmente toma a globalização e a dissolução das fronteiras nacionais como processos claramente definidos. No entanto, alguns historiadores começaram a questionar se essa "interconectividade" experimentada no início do século XXI pode não ser tão radical ou duradoura como se pensava inicialmente. Embora isso seja frequentemente exemplificado com o retorno de discursos nacionalistas - como o "America first" de Donald Trump, a campanha a favor do Brexit, ou o ressurgimento da xenofobia diante da migração em muitas partes do mundo - outros historiadores argumentam que se trata de uma reação contra a própria globalização. ${ }^{12}$ De qualquer forma, vozes críticas questionaram até que ponto essa dissolução das fronteiras nacionais que deu tanto ímpeto às perspectivas históricas transnacionais não é um fato histórico, mas parte da construção da globalização como objeto de estudo. Como Daniel Tröhler devidamente destacou: "A questão epistêmica crucial permanece quanto a se processos como a globalização podem ser mesmo descritos analiticamente, ou até que ponto a própria sociologia ou história contribuem para a construção de seu próprio objeto que, supostamente, está sendo simplesmente descrito” (TRÖHLER, 2011) ${ }^{13}$.

\section{Pesquisa em história transnacional da educação}

As últimas três décadas viram a produção de um número significativo de estudos em história da educação com foco em aspectos transnacionais do campo. 0 alcance dos conceitos e categorias analíticas propostos tem sido variado, e nem todos os autores empregam explicitamente o selo "transnacional" para descrever o que fazem. Como Rebecca Rogers (2019) sugere, o "transnacional” em pesquisa educacional histórica não é necessariamente uma abordagem ou uma metodologia, mas antes um ponto de vista, uma perspectiva, ou uma "postura”. É nosso propósito observar e desnaturalizar os conceitos e categorias analíticas usadas nessa "postura" e apontar os caminhos pelos quais eles direcionam, constrangem e tornam a pesquisa frutífera.

No seguinte panorama de tendências atuais no trabalho recente sobre história transnacional da educação, nós argumentamos que o que nos dias atuais chamamos de "história transnacional da educação" carrega camadas de significado que tanto se referem, frequentemente reagindo contra, a um discurso normativo de longa duração sobre educação internacional, quanto mencionam um projeto de pesquisa sobre transnacionalismo nas ciências históricas que não somente descreve, mas também tende a construir o mundo globalizado e conectado a que se refere (FUCHS, 2012; DROUX; HOFSTETTER, 2014; SOBE,

\footnotetext{
12 - Para uma visão geral de alguns dos argumentos recentes a favor e contra a história global, consultar a discussão entre Richard Drayton e David Motadel com Jeremy Adelman e David Bell, publicada em Drayton e Motadel (2018).

13 - N.T.: De acordo com os autores, é com base na percepção crítica de Tröhler que pretendem, no livro para o qual escrevem este capítulo introdutório, "explicitar o inevitável entrelaçamento da "realidade" histórica com os conceitos usados para descrevê-la e, em particular, com as categorias que empregamos para construir objetos específicos de estudo". Acrescentam que o livro consiste, "acima de tudo, um esforço de autorreflexividade, de reflexão sobre o que os historiadores da educação realmente fazem, com o objetivo de contribuir de maneira mais adequada para moldar o campo emergente da história transnacional da educação." (ROLDÁN VERA; FUCHS, 2019, p. 13).
} 
2013). Não pretendemos oferecer uma revisão exaustiva da literatura; ao invés disso, apresentamos um panorama das áreas de pesquisa em que a abordagem transnacional tem sido frutífera, e dos enfoques teóricos e metodológicos por elas mobilizados.

\section{Principais áreas de pesquisa}

\section{Interações internacionais e redes de educadores}

Essa pesquisa pode representar histórias que traçam as viagens e conexões internacionais de educadores proeminentes. Afastando-se da noção tradicional de "impacto educacional" em outras regiões, esses estudos levam em consideração as maneiras pelas quais outros contextos afetam as propostas pedagógicas das figuras que examinam ${ }^{14}$. Concebidos junto a narrativas de contágio e entrelaçamento, esses estudos tendem a ser mais celebradores do que críticos do embaçamento das fronteiras. Enquanto refletem sobre a especificidade dos contextos socioculturais em que os educadores operam, tendem a enfatizar as diferenças nas transformações específicas e adaptações de suas ideias, reagindo, desse modo, contra a afirmação da validade ou padronização internacionalmente consistente em valores educacionais.

\section{Histórias da educação coloniais e imperiais}

0 foco tradicional das histórias coloniais costumava ser a disseminação de conhecimento e educação das metrópoles para as colônias, assumindo implicitamente uma narrativa de como um cânone ocidental universalmente válido de conhecimento e valores cruzou fronteiras. No entanto, pesquisas recentes reconhecem as dinâmicas de poder que agem na disseminação de conhecimento e a agência local que reage contra, transforma e participa na construção do conhecimento educacional. Pesquisadores têm, dessa forma, voltado sua atenção ao entrelaçamento e às relações mútuas de influência entre colonizadores e colonizados, especialmente em estudos sobre educação nos impérios britânico, francês e belga, e também, embora menos, nos contextos português e espanhol (ALTBACH; KELLY, 1978; LINDMARK, 2000; WHITEHEAD, 2003; FISCHER-TINÉ, 2004; MADEIRA, 2006; BELLENOIT, 2007; ALLENDER, 2009; TSCHURENEV, 2011; OSSENBACH; DEL POZO ANDRÉS, 2011; GOODMAN; MCCULLOCH; RICHARDSON, 2009; ROGERS, 2013). Além disso, essa área de pesquisa reconhece as epistemologias "vernaculares", em uma crítica direta ao paradigma da universalidade do conhecimento educacional (SETH, 2007).

\section{A formação internacional da ciência educacional}

Essa categoria abrange estudos relacionados à maneira pela qual a educação se tornou uma disciplina profissional, com ênfase em congressos, revistas e instituições acadêmicas e profissionais internacionais (CHARLE; SCHRIEWER; WAGNER, 2004).

14 - Um exemplo é Bruno-Jofre e Schriewer (2012); ver também: Fuchs (2007). 
Alguns estudos examinam particularmente a emergência e desenvolvimento de organizações internacionais e sua promoção de modelos e ideias educacionais em todo o mundo, frequentemente historicizando os modos pelos quais o paradigma da educação internacional surgiu (KULNAZAROVA; YDESEN, 2017; FUCHS; SCHRIEWER, 2007; FUCHS, 2009; FUCHS, 2007; FUCHS, 2006; FUCHS, 2006a; BEECH, 2006; JONES; COLEMAN, 2005; GOODMAN, 2007; GOODMAN, 2012; RAFTERY, 2015). Outros mostram como objetos de pesquisa desenvolvidos pela ciência educacional foram construídos nos cruzamentos entre tendências internacionais e preocupações locais (SCHRIEWER; MARTÍNEZ, 2004; CARUSO, 2014).

\section{Histórias institucionais}

Esses estudos focam a internacionalização de modelos e currículos escolares, universidades e setor de educação não-formal, comparando-os entre países. Enquanto alguns desses estudos enfatizam a convergência de tendências em um modo bastante celebrativo de um programa ocidental de individualismo e cidadania liberal ${ }^{15}$; outros, embora reconhecendo o caráter "global" de tais instituições, questionam narrativas abrangentes sobre causas únicas (funcionais, simbólicas) para seu estabelecimento e desenvolvimento (CARUSO; ROLDÁN VERA, 2005; TRÖHLER; POPKEWITZ; LABAREE, 2011; ROLDÁN VERA, 2013; SCHRIEWER; CARUSO, 2005).

\section{Difusão de conhecimento pedagógico}

Essa é provavelmente a forma mais comum em que a pesquisa sobre história transnacional da educação aparece. Nos anos recentes, estudos sobre difusão colocaram ênfase muito maior em processos de tradução, apropriação e adaptação de conhecimento pedagógico em uma gama de contextos locais (BENAVOT; BRASLAVSK, 2007; ROLDÁN VERA; CARUSO, 2007; CARUSO et al.; 2014; COLLINS; ALLENDER, 2013). Com isso, e afastando-se de narrativas simplistas de contágio, desafiaram a própria ideia de "difusão", buscando, em vez disso, categorias alternativas como "hibridismo", "enculturação" ou a criação de "espaços educacionais transnacionais". Essa última abordagem propõe uma visão do transnacional como um domínio da construção de espaços temporários de transnacionalidade por meio de redes pessoais, da recepção de modelos de outros lugares, cooperação institucional, e da criação de fóruns internacionais (MÖLLER; WISCHMEYR, 2013; FUCHS; KESPER-BIERMANN; RITZI, 2011; BURKE; CUNNINGHAN; GROSVENOR, 2010; LOWE; MCCULLOCH, 2003; LAWN, 2008; MAYER; GROSVENOR, 2014; DEL POZO ANDRÉS, 2009; CARUSO, 2018; KOSLOWSKI, 2013).

\section{Estudos de gênero}

Publicações recentes no campo da pesquisa sobre gênero têm enfatizado relações transnacionais, especificamente de transferência e troca e influências mútuas, levandoas assim a focar novos atores e espaços (GOODMAN, 2002; CORTINA; ROMÁN, 2006;

15- Por exemplo: Ramirez, Suarez e Meyer (2007). 
ROGERS, 2014; MAYER, 2012; ALLENDER, 2016; RAFTERY; CLARKE, 2017; FITZGERALD; SMITH, 2014).

\section{Pesquisa sobre livros didáticos}

Estudos históricos recentes têm focado no caráter transnacional da produção e distribuição de livros didáticos, examinando especialmente o papel dos editores e as maneiras como seus interesses comerciais transnacionais moldam o conteúdo da educação (FUCHS; BOCK, 2018; ROLDÁN VERA, 2003). Comparações transnacionais de livros didáticos tendem também a reagir contra a visão simplista de que o conhecimento cruza fronteiras graças a sua validade universal, apontando, ao invés, que ele passa por diversas adaptações, tanto na tradução (literal e figurada) do conteúdo do livro didático quanto no próprio processo de ensino.

\section{Teorias e métodos}

A pesquisa sobre história transnacional da educação nas áreas identificadas acima faz uso implícito ou explícito de diversos insights teóricos, os quais nós resumimos nesta seção. Enquanto a corrente principal de pesquisa histórica transnacional não é altamente teorizada, a pesquisa transnacional em história da educação é mais densa teoricamente, principalmente devido à sua proximidade com a pesquisa no campo educacional. Essa proximidade significa também que as abordagens teóricas em uso na pesquisa educacional transnacional surgiram no interior das ciências sociais, como a sociologia, a teoria política e os estudos culturais, de cujo ponto de vista o campo da educação é usualmente pensado. Em que medida essas teorias carregam camadas de significado vindas do discurso normativo sobre educação internacional? Que considerações contextuais influenciaram os caminhos pelos quais elas construíram os objetos de pesquisa que pretendem descrever? Elas resultam de uma narrativa celebratória do embaçamento das fronteiras derivada das conotações de um comércio ou agenda política transnacionais? Ou são uma reação contra a crença de que o conhecimento educacional pode ter validade universal em diferentes partes do mundo?

\section{Teoria do Sistema-Mundo - Cultura-Mundo - Sociedade-Mundo}

Três abordagens teóricas "sistêmicas" dominam boa parte do modo como a história transnacional e uma história transnacional da educação têm sido feitas nos últimos anos (CARUSO, 2008). A primeira dessas, Teoria do Sistema-Mundo, é uma teoria historicamente fundamentada que afirma que o arranjo do mundo moderno como encontrado no início do capitalismo transatlântico no século XVI abriu caminho para a emergência de uma economia mundial que é um sistema em si mesmo e que constitui um nível global/ transnacional de causalidade (WALLERSTEIN, 1974). A teoria situa esse sistema mundial como marcado por uma divisão internacional de trabalho não regulamentada por qualquer estrutura política, que divide os países em centrais, semi-periféricos e periféricos, de acordo 
com a função que eles exercem na produção e consumo de bens e na capitalização e produção de tecnologia. Os países são conectados por relações de dependência econômica, e as fronteira são cruzadas pelas forças econômicas em ação (por meio de navegação comercial, tropas, mercados em expansão, e assim por diante). Abordagens históricas baseadas no Sistema-Mundo colocam sua ênfase primária no processo de formação de redes, na dissolução de fronteiras e na consciência do mundo como situado em um sistema internacional determinado por forças econômicas. A aderência a esse quadro produziu diversos trabalhos sobre a difusão de modelos racionalizados de escolarização moderna por agências governamentais ou missionários em todos os impérios ${ }^{16}$. Além disso, abordagens em Sistema-Mundo afırmam que, ao dissolver fronteiras, as relações econômicas globais/transnacionais produzem riqueza e pobreza, países ricos e pobres, provedores e consumidores; parte de sua missão é lançar luz sobre as trajetórias divergentes tomadas pelos diferentes participantes no sistema. Esse quadro foi significativo para a formulação de "teorias da dependência" econômica que influenciaram a conceitualização da educação no mundo em desenvolvimento durante a década de 1970, bem como a escrita de algumas histórias da educação ${ }^{17}$.

"Cultura-Mundo" é uma teoria macrossociológica e culturalista que pressupõe a existência de uma ordem/modelo cultural, global, baseado nas origens das sociedades ocidentais, cujas características são universalismo, individualismo, progresso, racionalismo e cidadania mundial. A teoria sugere ainda que esse modelo goza de validade universal, que a construção cognitiva de seus objetos é global por natureza, e que ele é promovido e disseminado por organizações transnacionais e "legitimado" pelos Estados-Nação. Outro princípio dessa teoria é sua ligação entre a origem de sistemas de educação em massa ao redor do mundo e a disseminação do modelo de Estado-Nação e a necessidade de (ritualmente) criar e educar a cidadania que o endossaria. Parte da "cultura-mundo" assim proposta é uma "gramática da educação", válida mundialmente, cujo estabelecimento foi acompanhado por um desenvolvimento institucional uniforme por todo o mundo. Isso explicaria o isomorfismo visto em estruturas, instituições e discursos educacionais na maior parte dos países ao redor do globo ${ }^{18}$.

Na visão de Schriewer (2003, p. 277), “cultura-mundo" é uma construção semântica "não completamente desconectada das estruturas predominantes na arena internacional". Tröhler (2011) considera a Teoria da Cultura-Mundo um relato linear e celebratório da globalização (a difusão de uma cultura-mundo) que, entretanto, mais do que descrever um fenômeno histórico, construiu a globalização como um objeto de estudo. Essa construção aconteceu com base em premissas epistemológicas assentadas em uma "linguagem da educação" histórica específica, derivada da tese de Max Weber sobre a ética protestante, que assume que a maior parte dos valores protestantes secularizados se espalharam em todo o mundo desde pelo menos o fim da Segunda Guerra Mundial.

\footnotetext{
16 - Ver as referências apresentadas em Caruso (2007, p. 829).

17 - Ver: Carnoy (1974).

18 - Ver, por exemplo: Lechner e Boli (2008); Li e Hicks (2016); Popkewitz (2009); Schriewer (2016).
} 
Finalmente, a Teoria da Sociedade-Mundo de Niklas Luhmann concebe a sociedade como um sistema mundial geral em cujo interior existem inúmeros sistemas menores (grupos, comunidades, instituições, nações), interconectados por processos complexos de comunicação, transcendendo fronteiras nacionais, e articulado em torno de subsistemas funcionais específıcos, como economia, justiça, religião, política e educação (LUHMANN; SCHORR, 1996). Nessa concepção, cada sistema ou subsistema tem a capacidade de reproduzir e reformar a si mesmo com base em sua própria história, tradição e valores. Ainda há momentos históricos específicos em que os pontos de referência internos do sistema parecem inadequados para alcançar certos objetivos; essa inadequação leva os atores a buscarem soluções em referências externas ao sistema (ou seja, em outros sistemas). Essas referências são então recontextualizadas e internalizadas a tal ponto que os elementos externos desses modelos são apagados e aparecem como nativos. Jürgen Schriewer desenvolveu uma correspondente "teoria da externalização" específica para o domínio educacional (SCHRIEWER, 1987) que influenciou a produção de alguns trabalhos em história da educação (SCHRIEWER; MARTÍNEZ, 2007; WALDOW, 2007).

\section{Teoria Pós-Colonial e estudos subalternos}

Teorias pós-coloniais - em suas variantes asiática, africana e latino-americana - representam uma crítica ao conceito etnocêntrico de modernidade. Elas afirmam que os processos de desenvolvimento do capitalismo, industrialização, secularização e antropocentrismo que começaram por volta do século XVI não foram uma criação europeia subsequentemente "difundida" para o resto do mundo via imposição da Europa em termos militares, comerciais e culturais. Antes, na visão pós-colonial, a modernidade foi o produto da interação da Europa com as pessoas que as forças europeias estavam conquistando e subjugando. Nesse sentido, escravidão e genocídio não são "aberrações" da modernidade, mas suas partes integrantes (MIGNOLO, 2011). Estudos pós-coloniais e subalternos criticam a alegada "universalidade" de conceitos ocidentais relacionados à produção de conhecimento, tais como "cultura", "tradição", "história" e "falta de história". Essa crítica acredita que tais conceitos, cunhados no processo de interação com sociedades não-ocidentais, distorcem, obscurecem e falham ao representar aquelas sociedades no processo de descrição e explicação mobilizado (SETH, 2010; DUSSEL, 1992). Os métodos históricos da teoria pós-colonial consistem em prestar atenção nos vários lugares de enunciação dos atores, desconstruindo os conceitos e categorias usadas para descrever a realidade colonial e tentando retraçar as estratégias de sobrevivência cultural empregadas pelas pessoas sujeitadas à regra violenta de outros poderes. No entanto, como Tim Allender (2016) notou, ao enfatizar a construção do sujeito colonizado, os estudos subalternos tendem a apagar o papel e a presença dos europeus em territórios coloniais, especialmente após sua independência.

A crítica pós-colonial e subalterna, bem como a historiografia educacional nela engajada, posiciona-se politicamente contra discursos de globalização e transnacionalismo que borram a assimetria das relações de poder entre colonizadores e colonizados ou aceitam prima facie modelos de transferência cultural operando de sociedades "mais avançadas" 
para "menos avançadas" no mundo. Além disso, essas abordagens rejeitam a validade universal de normas e valores (inclusive educacionais) e definem como sua principal agenda a desconstrução de normas e valores que foram enraizados em discursos políticos e historiográficos anteriores (SETH, 2007; ROLDÁN VERA, 2007).

\section{Redes}

Vários trabalhos relacionados a redes nas ciências sociais apoiam-se na premissa de Émile Durkheim segundo a qual o mundo é constituído por relações na primeira instância e por entidades individuais na segunda. Abordagens de redes examinam relações entre atores (indivíduos, organizações ou instituições), identificam os padrões que eles seguem e estudam o impacto desses padrões em processos de mudança social. A teoria ator-rede e a análise de rede social são metodologias específicas que tentam operacionalizar o conceito de rede e que são usadas no estudo do fenômeno transnacional em educação. A primeira considera que relações sociais são articuladas em redes de pessoas e objetos que se espalham através do espaço, não obstante as fronteiras políticas; tanto pessoas quanto objetos constantemente interagem entre si e afetam um ao outro, e, nesse sentido, possuem agência no interior da rede (LATOUR, 2005; FENWICK; EDWARDS, 2012; GRUNDER; HOFFMANN-OCON; METZ, 2013). A segunda visualiza as relações sociais como uma rede de ligações (amizade, relações econômicas, fluxos de informação, entre outros) entre indivíduos e organizações, e, baseada nisso, identifica a estrutura da rede de vínculos (seu grau de centralidade, densidade, mediação) e os padrões de relações existentes entre os atores (proximidade, mediação, conectividade, transitividade). Ambos os tipos de análise de rede rejeitam explicações baseadas somente em atributos categóricos dos atores, como classe, consciência de classe, afiliação política, crença religiosa, origem étnica, ou gênero; pelo contrário, constroem explicações derivadas dos padrões de relações estabelecidos entre os atores, que são em alguma medida independentes de suas vontades, crenças e valores. Métodos de redes são úteis para entender, entre outras coisas, mudança social, fluxos de informação e a difusão de inovações e modelos educacionais (ROLDÁN VERA; SCHUPP, 2005; GRUNDER; HOFFMANN-OCON; METZ, 2013; FUCHS, 2006; FUCHS, 2007; FUCHS; LINDMARK; LÜTH, 2007).

Uma vez que redes não respeitam fronteiras nacionais, suas abordagens tendem a borrá-las mais enfaticamente que outras. Entretanto, ao abstrair o contexto e a classe, a cultura e a intencionalidade dos atores, tendem a apagar as dinâmicas de poder assimétrico entre regiões e grupos. Além disso, abordagens de rede requerem um corpus de dados substancial e consistente, algo nem sempre possível na pesquisa histórica. Isso tem levado ao uso vago do conceito de "redes" como uma metáfora para a interconectividade dos sujeitos sem o aproveitamento de uma base empírica forte que pode dar à rede, ou ao seu estudo, um poder explanatório (ROLDÁN VERA, 2006). 


\section{Lending e borrowing ${ }^{19}$}

Metodologias focadas em torno dos conceitos de lending e borrowing são evidentemente uma reação ao paradigma da validade universal do conhecimento e valores educacionais e às narrativas de convergência de processos educacionais; essa resposta articula-se em atenção ao processo de sua adaptação a contextos locais. Recorrendo à teoria da externalização de Schriewer, Gita Steiner-Khamsi caracteriza o processo de "lending e borrowing" como constituído por três fases consecutivas: referência a um modelo externo (externalização), modificação local deste (re-contextualização), e metamorfose gradual em um modelo nativo (internalização). Essas fases também podem ser descritas como recepção ativa, implementação e indigenização (STEINER-KHAMSI, 2002, 2004). David Phillips, por sua vez, divide o "borrowing" em quatro fases: atração transnacional, decisão, implementação e internalização/indigenização. A primeira fase refere-se ao ímpeto externo e aos contextos sociais para processos de transferência. $\mathrm{Na}$ segunda fase, os participantes respondem a esse ímpeto por meio de vários estágios de tomada de decisão; então, a terceira fase integra modelos estrangeiros ao sistema nativo. Por último, na quarta fase, essa integração progride suficientemente longe do anteriormente modelo externo para ser considerada parte do sistema local (PHILLIPS, 2004). Esse conceito foi recentemente expandido para incluir processos não-intencionais de transferência, ou "borrowing" silencioso (STEINER-KHAMSI; WALDOW, 2012; RINGARP; WALDOW, 2016). Robert Cowen abre uma visão para além da política educacional; sua diferenciação entre transferência, tradução e troca potencialmente incorpora uma vasta gama de tipos de transferência e tenta reconciliar a análise da transferência com a dos contextos (COWEN, 2006; WALDOW, 2010). Os dois primeiros desses conceitos funcionam bem do ponto de vista da história da educação, porém, o modelo de transferência de Cowen, apesar de seu uso por sociólogos e comparatistas educacionais, ainda não foi explicitamente aplicado ao fenômeno histórico.

\section{Linguagens e conceitos}

Provavelmente a mais recente perspectiva transnacional na história da educação, a história das linguagens em educação deriva em parte da história das linguagens políticas e da história dos conceitos e da semântica histórica. Seus proponentes sugerem que as linguagens são quadros específicos, ou padrões de pensamento/fala/escrita sobre o educacional que são transnacionais e se referem de uma maneira mais ou menos explícita a ideais político-religiosos (TRÖHLER, 2011). 0 número de tais linguagens da educação é limitado; Tröhler identifica duas que perduram desde o século XVIII até os duas atuais: o Calvinismo suiço, baseado em uma visão de educação para a formação de valores

19 - N.T.: As palavras lending e borrowing, traduzidas ao português, referem-se ao ato de emprestar, sendo lending referido àquele que empresta e borrowing àquele que toma de empréstimo. Como em português não há termos específicos para operar esta distinção, decidimos manter no texto a terminologia em inglês. 
comunitários, ligado ao republicanismo clássico, e o Luteranismo alemão, cuja ênfase é o conceito humanista de Bildung como autocultivo e desenvolvimento individual.

Outras abordagens a esse respeito preferem focar a história de conceitos educacionais específicos, observando as formas nas quais o vocabulário que utilizamos para falar sobre educação desenvolveu novos significados durante os séculos XIX e XX no interior de um quadro de relações transnacionais, e como essas camadas de significado afetam como falamos de educação no presente (ROLDÁN VERA, 2014; TROTMAM; LEES; WILLOUGHBY, 2018).

\section{Transferência cultural, histoire croisée, shared history}

A abordagem da "transferência cultural", proposta primeiramente por pesquisadores franceses no campo dos estudos germânicos (ESPAGNE; WERNER, 1988), trata de processos de intercâmbio e influência mútuas e, em última instância, da capacidade dos objetos desses processos em mudarem sob observação, no contexto do Estado-Nação ${ }^{20}$. Tem passado por mais desenvolvimentos posteriores desde seu início, focando agora no conceito de "transfaire", que objetiva estudar "instrumentos simbólicos e técnicos produzidos e reproduzidos por circulação”. Assim, essa abordagem tenta um novo modo de explorar conexões, concomitâncias e interdependências, colocando o foco "em modalidades de ‘trans-ação' [transfaire]” e “processos de tradução e coprodução de veículos normativos e do tecido do qual a política é feita. Pensar em termos de inter-relações é central para esse esforço, de modo que se evite que a ideia de regiões incomensuráveis seja reintroduzida sob o disfarce de "transferência" ${ }^{21}$. Tal abordagem é próxima do conceito de histoire croisée proposto por Werner e Zimmermann, que busca investigar relações dessimétricas e a maneira pela qual os eventos evoluem e mudam por meio de entrelaçamentos (WERNER; ZIMMERMANN, 2003).

Ainda que frutíferas para a pesquisa em história da educação, abordagens baseadas na transferência mostram demasiada confiança, como Noah Sobe criticamente apontou, em "estratégias comparativas estreitamente concebidas" que requerem que o pesquisador "pare o fluxo do tempo de modo que um objeto transversal possa ser estabilizado e discernido". Na visão de Sobe, isso leva à construção de objetos de pesquisa artificiais que não levam em consideração "as transformações, continuidades e descontinuidades entre passados, presentes e futuros possíveis” (SOBE, 2013, p. 100; FONTAINE, 2015).

\section{Ciclo de normas}

Essa abordagem foca no desenvolvimento e juridificação de normas (FINNEMORE, 1993; FINNEMORE, 1996), enfatizando principalmente o nível do ator, as estruturas organizacionais relevantes e os efeitos desses processos. No entanto, a existência de normas não diz nada sobre o comportamento verdadeiro dos atores; o nível operacional da pesquisa sobre normas segrega esses dois aspectos.

20 - Alguns trabalhos sobre história da educação publicados nos mundos germanófono e francófono seguiram essa abordagem. Ver, por exemplo, Koinzer (2011); Mayer (2011); Fontaine (2015).

21 - Ver: http://transfaire.hypotheses.org/transacting, primeira página, acessado pela última vez em 21 de janeiro de 2019. 
Finnemore e Sikkink desenvolveram um modelo de três estágios do "ciclo vital" das normas para explicar o processo de desenvolvimento e implementação de uma norma internacional. A análise do estudo de caso resultante é baseada nesse modelo, que trata das normas que definem os padrões para o comportamento apropriado dos governos. 0 modelo diferencia entre "emergência da norma", "efeito cascata da norma" e "internacionalização da norma” (FINNEMORE; SIKKINK, 1998). Na primeira dessas três fases, emergem conceitos de normas, usualmente originados de contextos regionais e nacionais específicos e da formulação de direitos específicos que não implicam em si mesmos no estabelecimento de normas, mas são inicialmente ideias ou "compromissos cognitivos" (KATZENSTEIN, 1996) decorrentes de indivíduos que os formulam considerando suas situações e experiências de vida. Ideias somente se transformam em normas quando dão origem a expectativas coletivas em relação a certos comportamentos. "Empreendedores de normas" - indivíduos e organizações - buscam mover uma massa crítica de políticos e/ou governos para aceitarem essas novas normas. Se alcançam essa massa crítica e assim o "ponto de inflexão", eles avançam em direção à segunda fase, o "efeito cascata da norma”. Esse estágio é bem menos dependente dos contextos nacionais de produção da norma, à medida que durante esse estágio as normas se espalham para outros estados, com "seguidores da norma" emulando os "líderes da norma”. Por último, na terceira fase, as normas são internacionalizadas, codificadas em sistemas legais, e, então, tornam-se um componente natural da atividade política. Os atores cruciais na concepção e disseminação desses modelos, os mediadores entre o desenvolvimento das normas e sua implementação em relações internacionais, são as organizações internacionais estatais e não-estatais (FUCHS, 2007).

\section{Considerações finais}

Como na pesquisa histórica em geral, a abordagem transnacional na história da educação em particular é um campo em crescimento com uma larga variedade de tópicos que mobilizam uma ampla gama de diferentes instrumentos metodológicos e quadros teóricos. 0 panorama oferecido acima representa somente um breve olhar para uma vasta quantidade de novas pesquisas, e não pretende de modo algum proporcionar um relato exaustivo de toda a investigação feita durante a última década. Um olhar mais próximo

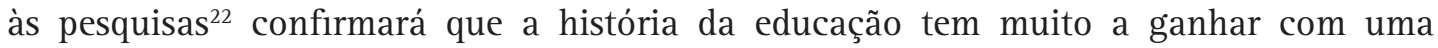
perspectiva que vai além das histórias nacionais da educação, levando em consideração as interdependências entre atores, instituições e conceitos através da história.

Contudo, a ideia de um novo "paradigma transnacional" também pede nossa autorreflexão enquanto disciplina. Nós devemos refletir sobre a situação social, geográfica e histórica das categorias e conceitos que usamos nesse tipo de pesquisa. A experiência do internacional é hoje a mesma que no período entreguerras ou nos anos 1970? Quanto desses primeiros significados nosso uso presente carrega? Estamos falando do mesmo "transnacional" se situados em Berlin em 1961, Kabul em 2001, ou Wuhan em 2020?

22 - N.T.: Aqui, os autores referem-se especificamente aos demais capítulos que compõem o livro de Fuchs e Roldán Vera (2019). Conferir nota de rodapé 4 
Como um adolescente, uma mulher, ou um casal de idosos experienciam o transnacional naqueles lugares? Até que ponto nossa experiência atual do transnacional articulou-se em conceitos que foram moldados por experiências de um tempo e lugar diferentes, e como essa experiência divergente, que implica uma "distância”, afeta a comunicação?

Como fizemos neste artigo com as categorias de "Educação Internacional”, é importante continuar explorando o inevitável entrelaçamento da "realidade" histórica com os conceitos usados para descrevê-la e, em particular, com as categorias que empregamos para construir objetos específicos de estudo. Quando escrevemos sobre transferência, adaptação, e transformação do conhecimento educacional; sobre o papel de agentes, redes e transformações institucionais, nós ainda estamos fazemos isso como uma reação crítica à crença do início do século XX na possibilidade de educar o mundo em valores comuns, compartilhados e transplantáveis? Podemos começar a ver outra dinâmica no modo como educadores, discursos, práticas, objetos e modelos pedagógicos transformam a si mesmos quando se mobilizam por diferentes lugares? Nós desistimos do ideal de construir uma ciência universal da educação e guiada e dirigida por uma missão humanitária? E como isso afeta a maneira como construímos nossos objetos transnacionais de pesquisa? Nós estamos apenas começando a lidar com estas questões. Este é um caminho excitante e promissor.

\section{Referências}

ACEVEDO, Ariadna; QUINTANILLA, Susana. La perspectiva global en la historia de la educación. Revista Mexicana de Investigación Educativa, Ciudad de México, v. 14, n. 40, p. 7-11, jan./mar. 2009.

ALLENDER, Tim. Learning abroad: the colonial educational experiment in India, 1813-1919. Paedagogica Historica, London, v. 45, n. 6, p. 707-722, dez. 2009.

ALLENDER, Tim. Learning femininity in Colonial India, 1820-1932. Manchester: Manchester University Press, 2016.

ALTBACH, Philip G.; KELLY, Gail P. Education and colonialism. New York: Longman, 1978.

ANDERSON, Benedict. Imagined communities: reflections on the origin and spread of nationalism. New York: Verso, 1991.

AUSTIN, John L. How to do things with words: the William James lectures. Cambridge: Harvard University Press, 1962.

$\mathrm{BACH}$, Olaf. Die erfindung der globalisierung: Entstehung und Wandel eines zeitgeschichtlichen Grundbegriffs. Frankfurt am Main: Campus, 2013.

BAGCHI, Barnita; FUCHS, Eckhardt; ROUSMANIERE, Kate (ed.). Connecting histories of education: transnational and cross-cultural exchanges in (Post) Colonial Education. New York: Berghahn, 2014.

BAL, Mieke. Travelling concepts in the humanities: a rough guide. Green College Lectures. Toronto: University of Toronto Press, 2002. 
BAYLY, Christopher A. et al. AHR conversation: on transnational history. American Historical Review, Oxford, v. 111, n. 5, p. 1441-1464, dez. 2006.

BEECH, Jason. Redefining educational transfer: international agencies and the (Re) production of educational Ideas. In: SPROGOE, Jonas, WINTHER-JENSEN, Thyge (ed.). Identity, education and citizenship: multiple interrelations. Frankfurt am Main: Peter Lang, 2006. p. 175-196.

BELLENOIT, Hayden J. A. Missionary education and empire in Late Colonial India, 1860-1920. London: Pickering \& Chatto, 2007.

BENAVOT, Aaron; BRASLAVSK, Cecilia. School knowledge in comparative and historical perspective: changing curricula in primary and secondary education. Dordrecht: Springer, 2007.

BOLI, John; THOMAS, George M. (ed.). Constructing world culture: international nongovernmental organizations since 1875. Stanford: Stanford University Press, 1999.

BOURNE, Randolph S. Trans-national America. The Atlantic, Boston, jul. 1916. Disponível em: https://www. theatlantic.com/magazine/archive/1916/07/trans-national-america/304838/. Acesso em: 29 mar. 2017.

BRAY, Mark. Comparative education and international education in the history of compare: boundaries, overlaps and ambiguities. Compare, London, v. 40, n. 6, p. 711-725, nov. 2010.

BRUNO-JOFRÉ, Rosa; SCHRIEWER, Jürgen. The global reception of John Dewey's thought: multiple refractions through time and space. New York: Routledge, 2012.

BURKE, Catherine; CUNNINGHAM, Peter; GROSVENOR, lan. "Putting education in its place": space, place and materialities in the history of education. History of Education, London, v. 39, n. 6, p. 677-680, nov. 2010.

CARNOY, Martin. Education as cultural imperialism. New York: David McKay, 1974.

CARUSO, Marcelo. Within, between, above, and beyond: (pre)positions for a history of the internationalisation of educational practices and knowledge. Paedagogica Historica, London, v. 50, n. 1-2, p. 10-26, abr. 2014.

CARUSO, Marcelo. World systems, world society, world polity: theoretical insights for a global history of education. History of Education, London, v. 37, n. 6, p. 825-840, nov. 2008. Disponível em: https://doi. org/10.1080/00467600802158256. Acesso em: 29 mar. 2017

CARUSO, Marcelo; ROLDÁN VERA, Eugenia. Pluralizing meanings: the monitorial system of education in Latin America in the early Nineteenth Century. Paedagogica Historica, London, v. 41, n. 6, p. 645-654, dez. 2005.

CARUSO, Marcelo et al. (ed.). Zirkulation und transformation: pädagogische grenzüberschreitungen in historischer perspektive. Köln: Böhlau, 2014.

CHARLE, Christophe; SCHRIEWER, Jürgen; WAGNER, Peter (ed.). Transnational intellectual networks: Forms of academic knowledge and the search for cultural identities. Frankfurt: Campus, 2004. 
CHRISTIN, Olivier (ed.). Dictionnaire des concepts nomades en Sciences humaines. Paris: Métailié, 2010. CLAVIN, Patricia. Defining transnationalism. Contemporary European History, Cambrigde, v. 14, n. 4 , p. 421-439, nov. 2005.

COHEN, Deborah; O'CONNOR, Maura. Introduction: comparative history, cross-national history, transnational history-definitions. In: COHEN, Deborah; O'CONNOR, Maura (ed.). Comparison and history: Europe in cross-national perspective. New York: Routledge, 2004. p. xi-1.

COLLINS, Jenny; ALLENDER, Tim (ed.). Knowledge transfer and the history of education. History of Education Review, Melbourne, v. 42, n. 2 (special), 2013.

CORTINA, Regina, SAN ROMÁN, Sonsoles (ed.). Women and teaching: global perspectives on the feminization of a profession. New York: Palgrave Macmillan, 2006.

COUNCIL OF EUROPE. Code of good practice in the provision of transnational education. [S. I.: s. n.], 2001. Adopted by the Lisbon Recognition Convention Committee at Its Second Meeting, Riga, 6 June 2001. Disponível em: http://www.coe.int/ t/dg4/highereducation/recognition/Code\%20of0/020 good\%20 practice_EN.asp. Acesso em: 29 mar. 2017.

COWEN, Robert. Acting Comparatively upon the educational world: puzzles and possibilities. Oxford Review of Education, Oxford, v. 32, n. 5, p. 561-573, nov. 2006.

CROSSLEY, Michael; WATSON, Keith. Comparative and international research in education: globalisation, context and difference. London: Routledge Palmer, 2003.

CROSSLEY, Pamela K. What is global history? Cambridge: Polity Press, 2007.

DEL POZO ANDRES, Maria Del Mar. The transnational and national dimensions of pedagogical ideas: the case of the project method, 1918-1939. Pedagogica Historica, London, v. 45, n. 4-5, p. 561-584, ago./ out. 2009.

DRAYTON, Richard; MORADEL, David. Discussion: the futures of global history. Journal of Global History, Cambridge, v. 13, n. 1, p. 1-21, fev. 2018.

DROUX, Joelle; HOFSTETTER, Rita (ed.). Internationalisation in education: issues, challenges, outcomes. Paedagogica Historica, London, v. 50, n. 1-2 (special), abr. 2014.

DUSSEL, Enrique D. 1492: El encubrimiento del otro: hacia el origen del 'mito de la modernidad': Santafé de Bogotá: Antropos, 1992. Conferencias de Frankfurt, octubre de 1992.

ENCYCLOPEDIA OF EDUCATIONAL RESEARCH. International education. In: BRICKMAN, William W.; MONROE, Walter S. (ed.). Encyclopedia of Educational Research. Rev. ed., New York: Macmillan, 1950. p. 617-627.

ESPAGNE, Michel; WERNER, Michael (ed.). Transferts: les rélations interculturelles dans l'espace francoallemand (XVIIle-XIXe siècles). Paris: Recherche sur les Civilisations, 1988. 
FARIES, John C. The rise of internationalism. New York: Gray, 1915.

FENWICK, Tara; EDWARDS, Richard (ed.). Researching education through actor network theory. Malden: Wiley-Blackwell, 2012.

FINNEMORE, Martha. International organizations as teachers of norms: the united nations educational, scientific, and cultural organization and science policy. International Organization, Cambridge, v. 47, n. 4, p. 565-597, 1993.

FINNEMORE, Martha. Norms, culture, and world politics: insights from sociology's institutionalism. International Organization, Cambridge, v. 50, n. 2, p. 325-347, 1996.

FINNEMORE, Martha; SIKKINK, Kathryn. International norm dynamics and political change. International Organization, Cambridge, v. 52, n. 4, p. 887-917, 1998.

FISCHER-TINÉ, Harald. National education, pulp fiction and the contradictions of colonialism: perceptions of an educational experiment in early-twentieth Century India. In: FISCHER-TINÉ, Harald; MANN, Michael (ed.). Colonialism as civilizing mission, cultural ideology and British India. London: Anthem, 2004. p. 229-247.

FITZGERALD, Tanya; SMITH, Elizabeth M. (ed.). Women educators, leaders and activists: educational lives and networks, 1900-1960. Basingstoke: Palgrave Macmillan, 2014.

FONTAINE, Alexandre. Aux heures suisses de l'école républicaine: un siècle de transferts culturels et de déclinaisons pédagogiques dans l'espace franco-romand. Paris: Demopolis, 2015.

FORMAN, Paul. Scientific internationalism and the weimar physicists: the ideology and its manipulation in Germany after World War I. Isis, Kingston, v. 64, n. 2, p. 150-180, jun. 1973.

FOX, Robert. Science without frontiers: cosmopolitanism and national interests in the world of learning, 1870-1940. Corvallis: Oregon State University Press, 2016.

FRIEDEMANN, Peter; HÖLSCHER, Lucian. Internationale. In: BRUNNER, Otto; CONCE, Werner; KOSELLECK, Reinhart (ed.). Geschichtliche grundbegriffe: historisches lexikon zur politisch-sozialen sprache in Deutschland. v. 3. Stuttgart: Klett-Cotta, 1982. p. 367-397.

FUCHS, Eckhardt. All the world into the school: world's fairs and the emergence of the school museum in the nineteenth century. In: LAWN, Martin (ed.). Modelling the future: exhibitions and the materiality of education. Oxford: Symposium Books, 2009. p. 51-72.

FUCHS, Eckhardt (ed.). Bildung international: historische perspektiven und aktuelle entwicklungen. Würzburg: Ergon-Verlag, 2006.

FUCHS, Eckhardt. Children's rights and global civil society. Comparative Education, London, v. 43, n. 3, p. 393-412, ago. 2007. 
FUCHS, Eckhardt. The creation of new international networks in education: the league of nations and educational organizations in the 1920s. Paedagogica Historica, London, v. 43, n. 2, p. 199-209, abr. 2007.

FUCHS, Eckhardt. Der völkerbund und die institutionalisierung transnationaler bildungsbeziehungen. Zeitschrift für Geschichtswissenschaft, Berlin, v. 54, n. 10, p. 888-899, out. 2006.

FUCHS, Eckhardt. Multilaterale bildungspolitik und transnationale zivilgesellschaft: universitätsbeziehungen in der zwischenkriegszeit. In: MILLER-KIPP, Gisela; ZYMEK, Bernd (eds.). Politik in der bildungsgeschichte: befunde, prozesse, diskurse. Bad Heilbrunn: Klinkhardt, 2006. p. 101-116.

FUCHS, Eckhardt. Networks and the history of education. Paedagogica Historica, London, v. 43, n. 2, p.185-197, abr. 2007.

FUCHS, Eckhardt (ed.). Transnationalizing the history of education. Comparativ, Leipzig, v. 22, n. 1 (special), 2012.

FUCHS, Eckhardt; ROLDÁN VERA, Eugenia (ed.). The transnational in the history of education: concepts and perspectives. London: Palgrave Macmillan, 2019.

FUCHS, Eckhardt; SCHRIEWER, Jürgen (ed.). Internationale bildungsorganisationen als global players in bildungspolitik und pädagogik. Zeitschrift für Pädagogik, Weinheim, v. 52, n. 2 (special), 2007.

FUCHS, Eckhardt; BOCK, Annekatrin (ed.). The palgrave handbook of textbook studies. New York: Palgrave Macmillan, 2018.

FUCHS, Eckhardt; KESPER-BIERMANN, Sylvia; RITZI, Christian (ed.). Regionen in der deutschen Staatenwelt: bildungsräume und transferprozesse im 19. Jahrhundert. Bad Heilbrunn: Klinkhardt, 2011.

FUCHS, Eckhardt; LINDMARK, Daniel; LÜTH, Christoph (ed.). Informal and formal cross-cultural networks in history of education. Paedagogica Historica, London, v. 43, n. 2 (special), 2007.

GOODMAN, Joyce. "Their market value must be greater for the experience they had gained": secondary school headmistresses and empire, 1897-1914. In: GOODMAN, Joyce; MARTIN, Jane (ed.). Gender, colonialism and education: the politics of experience. London: Woburn Press, 2002. p. 175-198.

GOODMAN, Joyce. Women and international intellectual co-operation. Paedagogica Historica, London, v. 48, n. 3, p. 357-368, jun. 2012.

GOODMAN, Joyce. Working for change across international borders: the association of headmistresses and education for international citizenship. Paedagogica Historica, London, v. 43, n. 1, p. 165-180, fev. 2007.

GOODMAN, Joyce; McCULLOCH, Gary; RICHARDSON, William. "Empires Overseas" and "Empires At Home": postcolonial and transnational perspectives on social change in the history of education. Paedagogica Historica, London, v. 45, n. 6, p. 695-706, dez. 2009.

GRUNDER, Hans-Ulrich; HOFFMANN-OCON,Andreas; METZ,Peter (ed.). Netzwerke in bildungshistorischer perspektive. Bad Heilbrunn: Klinkhardt, 2013. 
HEBERT, Yvonne; ABDI, Ali A. Critical perspectives on international Education. Rotterdam: Sense, 2013. IRIYE, Akira. Global and transnational history: the past, present, and Future. Basingstoke: Palgrave Macmillan, 2013.

IRIYE, Akira; SAUNIER, Pierre-Yves (ed.). The palgrave dictionary of transnational history: from the mid19th century to the present day. London: Palgrave Macmillan, 2009.

JONES, Phillip W; COLEMAN, David. The united nations and education: multilateralism, development and globalization. London: Routledge, 2005.

KATZENSTEIN, Peter J. (ed.). The culture of national security: norms and identity in world politics. New York: Columbia University Press, 1996.

KEMÉNY, Franz. L'enseignement international: histoire, état actuel, avenir. Ostende: Bureau International de Documentation Educative, 1914.

KOBEL, Oskar. Weltpädagogik. Die Neue Erziehung, Berlin, n. 1, p. 729-733, 1919.

KOERRENZ, Ralf; BLICHMANN, Annika; ENGELMANN, Sebastian. Alternative schooling and new education: European concepts and theories. Cham: Springer, 2018.

KOINZER, Thomas. Auf der suche nach der demokratischen schule: amerikafahre, kulturtransfer und schulreform in der bildungsreformära der bundesrepublik deutschland. Bad Heilbrunn: Klinkhardt, 2011.

KOSELLECK, Reinhart. Futures past: on the semantics of historical time. New York: Columbia University Press, 2004.

KOSLOWSKI, Steffi. Die new era der new education fellowship: ihr beitrag zur internationalität der reformpädagogik im 20. Jahrhundert. Bad Heilbrunn: Klinkhardt, 2013.

KULNAZAROVA, Aigul; YDESEN, Christian (ed.). UNESCO Without Borders: educational campaigns for international understanding. London: Routledge, 2017.

LAQUA, Daniel. The age of internationalism and belgium, 1880-1930: peace, progress and prestige. Manchester: Manchester University Press, 2013.

LATOUR, Bruno. Reassembling the social: an introduction to actor-networktheory. Oxford; New York: Oxford University Press, 2005.

LAWN, Martin (ed.). An Atlantic crossing? The work of international examination inquiry, its researchers, methods and influence. Oxford: Symposium Books, 2008.

LECHNER, Frank J.; BOLI, John. World culture: origins and consequences. Malden: Wiley-Blackwell, 2005. Reprint Oxford: Wiley-Blackwell, 2008. 
LI, Xue; HICKS, Alexander. World polity matters: another look at the rise of the nation-state across the world, 1816 to 2001. American Sociological Review, Chicago, v. 81, n. 3, p. 596-607, ago. 2016.

LINDMARK, Daniel (ed.). Education and colonialism: Swedish schooling projects in colonial areas, 16381878. Umea: Umea University, 2000.

LITTLE, Angela W. International and comparative education: what's in a name?. Compare, London, v. 40, n. 6, p. 845-852, dez. 2010

LOWE, Roy; MCCULLOCH, Gary. Introduction: centre and peripherynetworks, space and geography in the history of education. History of Education, London, v.32, n. 5, p. 457-459, set. 2003.

LUHMANN, Niklas; SCHORR, Karl Eberhard (ed.). Zwischen system und umwelt: fragen an die padagogik. Frankfurt am Main: Suhrkamp, 1996.

MADEIRA, Ana Isabel. Framing concepts in colonial education: a comparative analysis of educational discourses at the turn of the nineteenth to the twentieth century. In: SPROGØE, Jonas; WINTHER-JENSEN, Thyge (ed.). Identity education and citizenship: multiple interrelations. Frankfurt am Main: Peter Lang, 2006, p. 225-238.

MAYER, Christine. Female education and the cultural transfer of pedagogical knowledge in the eighteenth century. Paedagogica Historica, London, v. 48, n. 4, p. 511-526, ago. 2011

MAYER, Christine. GROSVENOR, lan. (ed.). Transnational circulation of reform ideas and practices: the example of the experimental and community schools (Versuchs- und Gemeinschaftschulen) in Hamburg (1919-1933). Paedagogica Historica, Londres, v. 50, n. 5 (special), 2014.

METZLER, Gabriele. Internationale wissenschaft und nationale kultur: Deutsche physiker in der internationalen community 1900-1960. Gottingen: Vandenhoeck \& Ruprecht, 2000.

MIDDELL, Matthias. NAUMANN, Katja. Global history and the spatial turn: from the impact of area studies to the study of critical junctures of globalization. Journal of Global History, Cambridge, v. 5, n. 1, p.149-170, fev. 2010.

MIGNOLO, Walter D. The darker side of western modernity: global futures, decolonial options. Durham: Duke University Press, 2011.

MOLLER, Esther. WISCHMEYER, Johannes (ed.). Transnationale bildungsraume: wissenstransfers im schnittfeld von kultu politik und religion. Gottingen: Vandenhoeck \& Ruprecht, 2013.

OESTREICH, Paul. Pädagogischer internationalismus? Die Neue Erziehung, Berlin, v. 13, p. 528-530,1931.

OSSENBACH, Gabriela; DEL POZO ANDRÉS, Maria del Mar (ed.). Lost empires, regained nations: postcolonial models, cultural transfers and transnational perspectives in Latin America (1870-1970). Paedagogica Historica, London, v. 47, n. 5 (special). 2011. 
OSSENBACH, Gabriela; DEL POZO ANDRÉS, Maria del Mar. Postcolonial models, cultural transfers and transnational perspectives in Latin America: a research agenda. Paedagogica Historica, London, v. 47, n. 5, p. 579-600, set. 2011.

OXFORD ENGLISH DICTIONARY. Internationalism, internationality, internationalize. In: OXFORD ENGLISH DICTIONARY. 2. ed., v. 7, Oxford: Clarendon Press, 1989. p. 1124.

PERNAU, Margrit. Transnationale geschichte. Gottingen and Stuttgart: Vandenhoeck \& Ruprecht, 2011.

PHILLIPS, David. Educational policy borrowing: historical perspectives. Oxford: Symposium Books, 2004.

POCOCK, John G. A. Politics, language, and time: essays on political thought and history. Chicago: University of Chicago Press, 1989. First published 1971 by Atheneum, New York.

POPKEWITZ, Thomas S. Globalizing globalization: the neo-institutional concept of a world culture. National Society for the Study of Education, London, v.108, n. 2, p. 29-49, nov. 2009

RAFTERY, Deirdre. Teaching sisters and transnational networks: recruitment and education expansion in the long nineteenth century. History of Education, London, v. 44, n. 6, p. 717-728, out. 2015.

RAFTERY, Deirdre. CLARKE, Marie (ed.). Transnationalism, gender and the history of education. London: Routledge, 2017.

RAMIREZ, Francisco 0.; SUAREZ, David; MEYER, John W. The worldwide rise of human rights education. In: BENAVOT, Aaron; BRASLAVSK, Cecilia (ed.). School knowledge in comparative and historical perspective: changing curricula in primary and secondary education. Dordrecht: Springer, 2007. p. 35-52.

RAYWARD, W. Boyd (ed.). Information beyond borders: international cultural and intellectual exchange in the belle epoque. Farnham: Taylor \& Francis, 2014.

RINGARP, Johanna. WALDOW, Florian. From "Silent Borrowing" to the international argument-legitimating swedish educational policy from 1945 to the present day. Nordic Journal of Studies in Education Policy, London, v. 2, n. 1, jun. 2016.

RITTBERGER, Volker. ZANGL, Bernhard. Internationale organisationen-politik und geschichte. 3. ed. Opladen: Springer, 2003.

ROGERS, Rebecca. A frenchwoman's imperial story: madame luce in nineteenth century Algeria. Stanford: Stanford University Press, 2013.

ROGERS, Rebecca. Congregações femininas e difusão de um modelo escolar: uma história transnacional. Pro-Posições, Campinas, v. 25, n. 1, p. 55-74, jan./abr. 2014.

ROGERS, Rebecca. Conversations about the transnational: reading and writing the empire in the history of education. In: FUCHS, Eckhardt; ROLDÁN VERA, Eugenia (ed.). The transnational in the history of education: concepts and perspectives. London: Palgrave Macmillan, 2019. p. 101-124. 
ROLDÁN VERA, Eugenia. Export as import: James Thomson's civilizing mission in South America. In: CARUSO, Marcelo; ROLDÁN VERA, Eugenia (ed.). Imported modernity in post-colonial state formation: the appropriation of political, educational and cultural models in nineteenth-century Latin America. Frankfurt am Main: Peter Lang, 2007. p. 231-276.

ROLDÁN VERA, Eugenia. La perspectiva de los lenguajes en la historia de la educación. Ariadna Histórica, Lojona Biscaia, n. 3, p. 7-14, out. 2014. Disponível em: http://www.ehu.es/ojs/index.php/Ariadna/issue/ view/1008. Acesso em: 29 mar. 2017

ROLDÁN VERA, Eugenia. Para desnacionalizar la historia de la educación: reflexiones en torno a la difusión mundial de la escuela lancasteriana en el primer tercio del siglo XIX. Revista Mexicana de Historia de la Educación, Ciudad do México, v. 1, n. 2, p. 171-198, 2013. Disponível em: http://www.somehide.org/ numero-2 -201 3.html. Acesso em: 29 mar. 2017.

ROLDÁN VERA, Eugenia. The British book trade and Spanish American Independence: education and knowledge transmission in transcontinental perspective. Aldershot: Ashgate, 2003.

ROLDÁN VERA, Eugenia; CARUSO, Marcelo (ed.). Imported modernity in post colonial state formation: the appropriation of political, educational and cultural models in nineteenth-century Latin America. Frankfurt am Main: Peter Lang, 2007.

ROLDÁN VERA, Eugenia; Bridges over the Atlantic: a network analysis of the introduction of the monitorial system of education in early-independent Spanish America. Comparativ, Leipzig, v. 15, n. 1 (special), p. 58-93, 2005.

ROLDÁN VERA, Eugenia; SCHUPP, Thomas. Network analysis in comparative social sciences. Comparative Education, London, v. 42, n. 3, p. 405-429, dez. 2006.

ROLDÁN VERA, Eugenia; FUCHS, Eckhardt. The Transnational in the History of Education. In: FUCHS, Eckhardt; ROLDÁN VERA, Eugenia (ed.). The transnational in the history of education: concepts and perspectives. London: Palgrave Macmillan, 2019. p.1-47.

SAUNIER, Pierre-Yves. Transnational history. Basingstoke: Palgrave Macmillan, 2013.

SCHRIEWER, Jürgen (ed.). Discourse formation in comparative Education. 3. ed. Frankfurt am Main: Peter Lang, 2009.

SCHRIEWER, Jürgen. Globalisation in education: process and discourse. Policy Futures in Education, London, v. 1, n. 2, p. 271-283, jun. 2003.

SCHRIEWER, Jürgen. Vergleich als methode und externalisierung der welt: vom umgang mit alteritat in reflexionsdisziplinen. In: BAECKER, Dirk; MARKOWITZ, Jurge; STICHWEH, Rudolf (ed.). Theorie als passion: niklas luhmann zum 60. geburtstag. Tyrell e Helmut Willke. Frankfurt am Main: Suhrkamp, 1987. p. 629-668.

SCHRIEWER, Jürgen (ed.). World culture re-contextualised: meaning constellations and pathdependencies in comparative and international education research. London: Routledge, 2016. 
SCHRIEWER, Jürgen; MARTíNEZ, Carlos. Constructions of internationality in education. In: STEINERKHAMSI, Gita (ed.). The global politics of educational borrowing and lending. New York: Teachers College Press, 2004. p. 29-53.

SCHRIEWER, Jürgen; MARTíNEZ, Carlos. ¿ldeologia educativa mundial o reflexión idiosincrática? El discurso pedagógico en España, Rusia (Unión Soviética) y China del siglo XX. Revista de Educación, Madri, v. 343, p. 531-557, jan. 2007.

SCHRIEWER, Jürgen; CARUSO, Marcelo (ed.). Nationalerziehung und universalmethode: fruhe formen schulorganisatorischer globalisierung. Comparativ, Leipzig, v. 15, n. 1 (special), 2005.

SETH, Sanjay. Subject lessons: the western education of Colonial India. Durham: Duke University Press, 2007.

SETH, Vanita. Europe’s Indians: producing racial difference, 1500-1900. Durham: Duke University Press, 2010.

SKINNER, Quentin. Visions of politics. 3 v. Cambridge: Cambridge University Press, 2002.

SLUGA, Glenda. Internationalism in the age of nationalism. Philadelphia: University of Pennsylvania Press, 2013.

SOBE, Noah W. Entanglement and transnationalism in the history of American education. In: POPKEWITZ, Thomas S. (ed.). Rethinking the history of education: transnational perspectives on its questions, methods and knowledge. Basingstoke: Palgrave Macmillan, 2013. p. 93-107.

STEINER-KHAMSI, Gita (ed.). The global politics of educational borrowing and lending. New York: Teachers College Press, 2004.

STEINER-KHAMSI, Gita. Re-framing educational borrowing as a policy strategy. In: CARUSO, Marcelo; TENORTH, Heins-Elmar (ed.). Internationalisierung: semantik und bildungssystem in vergleichender perspektive. Frankfurt am Main: Peter Lang, 2002. p. 57-89.

STEINER-KHAMSI; WALDOW, Florian (ed.). Policy borrowing and lending in education. London: Routledge, 2012.

TACKE, Otto. Die vorbereitung der aufnahme deutschlands in den völkerbund durch die schulen. Die Neue Erziehung, Berlin, v. 6, , p. 449-452, 1924.

TRÖHLER, Daniel. Languages of education: protestant legacies, national identities, and global aspirations. New York: Routledge, 2011.

TRÖHLER, Daniel; POPKEWITZ, Thomas S.; LABAREE, David F. (ed.). Schooling and the making of citizens in the long nineteenth century: comparative visions. New York: Routledge, 2011.

TROTMAN, Dave; LEES, Helen E; WILLOUGHBY, Roger (ed.). Education studies: the key concepts. Abingdon; New York: Routledge, 2018. 
TSCHURENEV, Jana. Incorporation and differentiation: popular education and the imperial civilizing mission in the early nineteenth century India. In: WATT, Carey A.; MANN, Michael (ed.). Civilizing missions in colonial and postcolonial South Asia: from improvement to development. London: Anthem, 2011. p. 93-124.

TYRRELL, lan. Reflections on the transnational turn in United States history: theory and practice. Journal of Global History, Cambridge, v. 4, p. 453-474, nov. 2009.

VALLE, Javier M. Supranational education: a new field of knowledge to address educational policies in a global world. Journal of Supranational Policies of Education, Madri, v.1, p. 7-30, fev. 2013.

WALDOW, Florian. Die internationale konjunktur standardisierter messungen von schi.ilerleistung in der ersten halfte des 20. jahrhunderts und ihr niederschlag in Deutschland und Schweden. Jahrbuch für Pädagogik, Berlin, v. 22, n. 1, p. 75-86, 2010.

WALDOW, Florian. Ökonomische strukturzyklen und internationale dskurskonjunkturen: zur entwicklung der schwedischen bildungsprogrammatik, 1930-2006. Frankfurt am Main: Peter Lang, 2007.

WALLERSTEIN, Immanuel Maurice. Capitalist agriculture and the origins of the european worldeconomy in the sixteenth century. New York: Academic Press, 1974.

WERNER, Michael; ZIMMERMANN, Benedicte. Penser I'histoire croisée: entre empirie et réflexivité. Annale, Paris, v. 58, n. 1, p. 7-36, fev. 2003.

WHITEHEAD, Clive. Overseas education and British colonial education 1929-63. History of Education, London, v. 32, n. 5, p. 561-575, set. 2003.

Eugenia Roldán Vera é pesquisadora do Departamento de Investigaciones Educativas del Cinvestav, México. Suas linhas de investigação são a difusão transnacional de modelos educativos, a história da escola e dos livros escolares e a história dos conceitos educativos nos séculos XIX e XX, temas sobre os quais publicou cinco livros e mais de 60 artigos em revistas especializadas e capítulos de livro. De 2016 a 2019 foi diretora da Revista Mexicana de Historia de la Educación.

Eckhardt Fuchs é Diretor do Georg Eckert Institute for International Textbook Research e Professor de História da Educação / Educação Comparada na Technical University Braunschweig (Alemanha). Seus interesses de pesquisa incluem história global da educação moderna, políticas de educação internacional e desenvolvimento de livros didáticos. Publicou 20 livros e mais de 100 artigos e capítulos sobre essas questões, incluindo The Palgrave Handbook of Textbook Studies (2018). Atuou como presidente da ISCHE de 2012 a 2015. 